Journal of Lake Sciences, Vol. 10, Suppl., pp393-410 1998.

Copyright $@ 1998$ by Science Press, Beijing.

Printed in P. R. China. All rights reserved.

\title{
Use of Triangular TN-TP-SRSi Diagrams to Evaluate Nutrient Ratio Dynamics Structuring Phytoplankton Assemblage*
}

\author{
Katrin Teubner ${ }^{1}$ and Thomas Teubner ${ }^{2}$ \\ ${ }^{1}$ Institut für Limnologie, Österreichische Akademie der Wissenschaften, \\ Gaisberg 116, A-5310-Mondsee, Austria \\ ${ }^{2}$ Institut für Kristallzüchtung im Forschungsverbund Berlin e.V., \\ Rudower Chaussee 6, D-12489 Berlin, Germany
}

\begin{abstract}
To show the relative availability of nitrogen, phosphorus and silica for diatoms as well as non-siliceous algae in phytoplankton communities triangular diagrams are most appropriate. Triangular diagrams for TN-TP-SRSi show the nutrient ratios TN: TP, SRSi:TN and SRSi:TP in proportion to each other at the same time.

Comparison of waters, grouped according to their limnological characteristics, indicate that these groups have also different seasonal dynamics of TN, TP and SRSi in proportion to each other. From these groups, which include meso-eutrophic and hypertrophic, shallow and deep, polymictic and dimictic lakes, only the group of "flushed, hypertrophic polymictic lakes" has a high seasonal dynamic of the ratios of all three macronutrients. Moreover the relative availability of TN:TP-ratios changes from $>16: 1$ in spring to $<16: 1$ in summer. Significant changes in phytoplankton structure are associated with this high dynamic of the nutrient ratios. Considerable changes in the share of cyanobacteria to diatom biomass during summer are synchronised with a powerful modification of the relative availability of TN-TP-SRSi as illustrated by the triangular diagrams.

For practical purposes trophic situations are most commonly evaluated from concentrations of a single nutrient or a nutrient ratio, such as N:P. However, a complex assessment would often be more appropriate. In this context triangular diagrams have the benefit of synoptically presenting relative nutrient availability for phytoplankton communities as a whole.
\end{abstract}

Keywords: eutrophication, riverine lakes, N:P:Si ratios, cyanobacteria

\section{Introduction}

Considering that phytoplankton communities consist of siliceous and non-siliceous algae, it is appropriate to reflect on the $\mathrm{N}, \mathrm{P}$ and $\mathrm{Si}$ resources. Assuming, that these three macroelements are of decisive importance for algae growth, a graphic method to show the complex relation between these three elements seems appropriate. The geometrical illustrations of three components in rela-

\footnotetext{
* Received 1997-02-25; accepted 1998-03-27.
} 
tion to each other evolved from GIBBS (1878) to describe thermodynamic properties. However, such triangular diagrams become increasingly important in limnology. This application was used to represent complex relations between concentrations of substances by VAN DAM et al. (1981) and BAILEY-WATTS and KIRIKA (1987), to show physiological relationships of organisms by SANDGREN (1988) or to compare the dynamic of colonisation strategies by PINTO and MORAIS (1994). However, in result of such triangular diagrams it is not the absolute amount but the ratios between three components which are shown. Therefore the nitrogen, phosphorus and silicon resources can be described in triangular diagrams as nutrient ratios of these three elements. It is well established, that aside of the absolute nutrient concentrations the ratio of the macroelements is of importance for resource competition in plankton communities (TILMAN, 1982).

The aim of this study is a comparison of seasonal nutrient dynamics in lakes, which are different in their trophic level and phytoplankton structure. Moreover, the seasonal changes in nutrient ratios will be discussed in relationship to seasonal phytoplankton alterations.

\section{Materials and methods}

Samples were taken from 8 lakes in Berlin-Brandenburg in Germany. Langer See (LANS), Großer Müggelsee (MUES), Flakensee (FLAS), Kiessee (KIES) and Krumme Lake (KRUL) are lakes on the periphery of the city of Berlin. The inlet waters of some flushed river lakes were sampled additionally (inlet of Großer Müggelsee (MUEZ) and Flakensee (Woltersdorfer Schleuse, FLZW, Löcknitz FLZL). Parsteiner See (PARS), Rosinsee (ROSS) and Großer Plagesee (GPLA) are part of the biosphere reserve "Schorfheide-Chorin" in Brandenburg, in the north of Berlin. Basic limnological data characterising the 8 lakes are summarised in Table 1.

Tablē 1. Morphometric, average physical, chemical and biological data of the investigated lakes. (1990-93, inlet waters excluded, morphological data from ANWAND, 1973)

\begin{tabular}{lcccccccc}
\hline lake (abbr.) & LANS & MUES & FLAS & KIES & PARS & ROSS & KRUL & GPLA \\
\hline Maximum depth $[\mathrm{m}]$ & 7 & 7.5 & 8.5 & 4.5 & 27 & 9 & 4.8 & 5 \\
lake area $\left[\mathrm{km}^{2}\right]$ & 1.53 & 7.70 & 0.73 & 0.20 & 11.00 & 0.20 & 0.15 & 0.78 \\
secchi depth $[\mathrm{m}]$ & 0.9 & 1.6 & 2.1 & 1.4 & 4.4 & 3 & 0.8 & 1.8 \\
conductivity $\left[\mathrm{mS} \cdot \mathrm{m}^{-1}, 20^{\circ} \mathrm{C}\right]$ & 59 & 61 & 86 & 88 & 47 & 53 & 18 & 23 \\
total nitrogen $\left[\mu \mathrm{mol}^{-1} \mathrm{l}^{-1}\right]$ & 107 & 87 & 47 & 62 & 56 & 84 & 105 & 85 \\
total phosphorus $\left[\mu \mathrm{mol} \cdot \mathrm{l}^{-1}\right]$ & 7.05 & 6.67 & 5.43 & 1.52 & 0.54 & 0.75 & 2.36 & 0.71 \\
soluble react. Silicon $\left[\mu \mathrm{mol} \cdot \mathrm{I}^{-1}\right]$ & 122 & 102 & 76 & 29 & 6.8 & 11 & 3.3 & 3.6 \\
\hline
\end{tabular}

Integrated samples were taken monthly from the 11 waters from 1990-1991. This sample frequency was continued for Langer See, Kiessee, Rosinsee and Parsteiner See in 1992. A biweekly interval was followed in Großer Müggelsee and Flakensee including the inlet waters (MUEZ, FLZL, FLZW) in 1992-93. All samples represented the mixed layer during temporary stratification. The light availability for phytoplankton was evaluated by the ratio of mixing depth $\left(\mathrm{z}_{\text {mix }}\right)$ to euphotic zone $\left(\mathrm{z}_{\mathrm{eu}}\right)$, derived from vertical profiles of temperature and irradiance (VOLLENWEIDER, 1955). 
Biovolume of phytoplankton was estimated according to the UTERMÖHL method. The mean value of the normal or the log-normal distribution was selected for abundance distribution (single cells, filaments or number of colonies) depending on which fitted better.

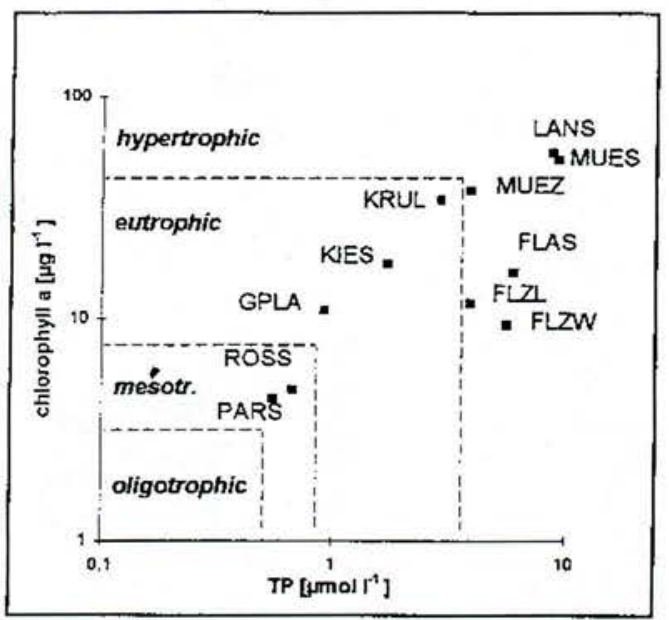

Fig.1 Relationship between chlorophyll-a and total phosphorus concentration in the 11 wa-

ters. The trophic levels are indicated by the averaged data of the June-September period according to FORSBERG \& RYDING (1980).

Diatoms were prepared in a special gentle way to keep both thecae of each frustule together (Teubner, 1995). This preparation technique allowed the measurement of the cell dimension in girdle view in addition to the valve diameter for different species and cell size. For the biovolume estimation of unicellular centric diatom species the counts of each sample fixed with Lugol's solution were combined with counts from a permanent slide.

The step-wise extraction of limnological parameters was repeated in PCA until the first two components represent more than $80 \%$ of total variance ( 8 limnological variables in Fig. $2 \mathrm{~b}$, cases: 11 waters represented by averaged data). These limnological parameters extracted by principal component analysis (PCA) were included in the hierarchical cluster analysis (HCA, Fig. 2a). Algal species never exceeding $10 \%$ of total biovolume during the investigated period were excluded from PCA. Step-wise species extraction was repeated in PCA until the first two components represent $40 \%$ of total variance (32 algal taxa in Fig. 3, cases: 34 investigated lake-years of the 11 waters). This multivariate analyses were based on relative biovolumes of the algae species.

Logarithmic data were standardised for multivariate statistical analyses using the computer program STATGRAPHICS plus 2.0 (STSC, inc. USA).

Triangular diagrams based on seasonal data (spring: March-May, summer: June-August, autumn: September-November, winter: December-February) were created in GRAPHER for Windows 4.0, Golden Software, Inc.

The data basis for Figs. 5, 6 and 7 were seasonal concentrations of total nitrogen (TN), total phosphorus (TP) and soluble reactive silicon (SRSi). For showing the relative nutrient availability 
total concentrations (TN, TP) as well as concentrations of soluble fractions (SRSi) were considered. In contrast to the conservative element, silicon which is recycled at longer intervals ( $>50$ days) phosphorus.
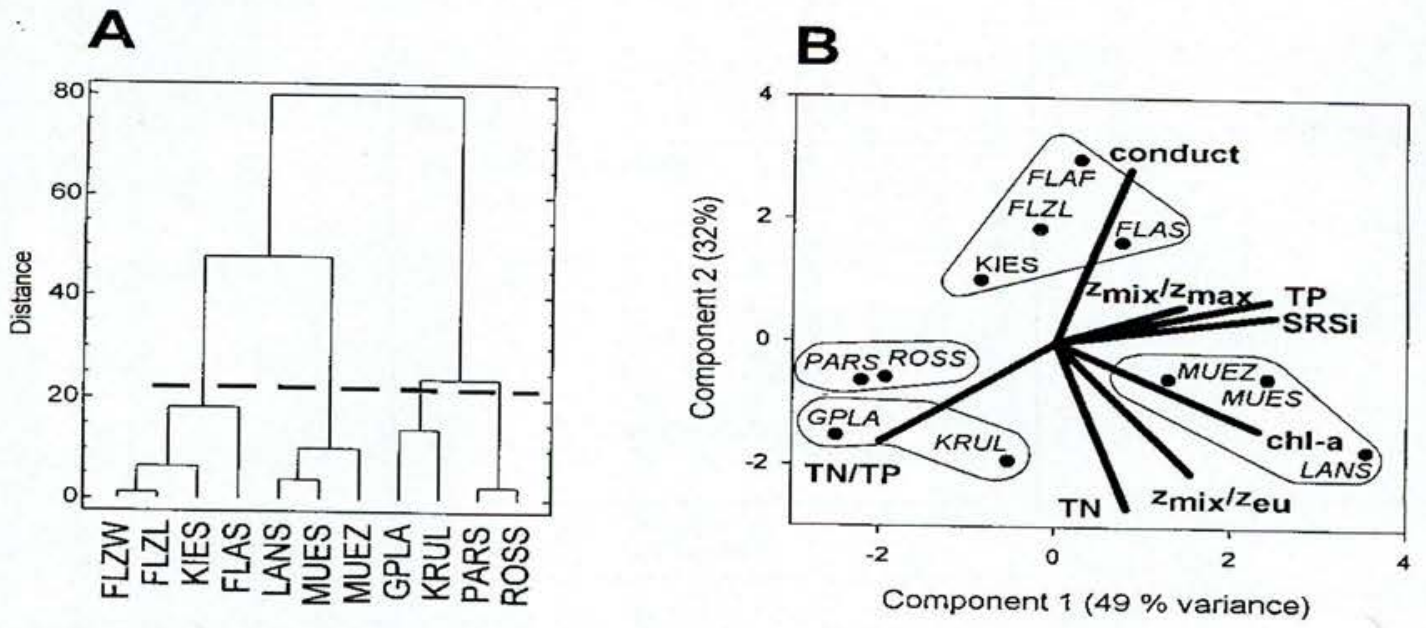

Fig. 2 a, b. Grouping of the 11 waters according to limnological characteristic. A and B are based on the same matrix of averaged limnological data (cf. original data in Table 1). A: Dendrogram of hierarchical cluster analyses. The broken line separates four groups of waters. Method: squared Euclidean distance, Ward linkage. B: Plot of the second versus the first principal component for limnological variables (vectors) and distribution pattern of the waters (points). Grouping of waters according to clusters in A. Abbreviations of limnological parameters: conductivity (conduct), concentration of chlorophyll-a (chl-a), soluble reactive silicon (SRSi), total nitrogen (TN) and total phosphorus (TP), ratio of TN:TP (TN/TP), ratio mixed depth to euphotic depth $\left(\mathrm{z}_{\text {mix }} / \mathrm{z}_{\mathrm{eu}}\right)$ and to maximal water depth $\left(\mathrm{z}_{\operatorname{mix}} / \mathrm{z}_{\max }\right)$ respectively. Abbr. of waters: FLAS-Flakensee, FLZL-Flakensee inlet Löcknitz, FLZW Flakensee inlet Woltersdorfer Schleuse, GPLAGroßer Plagesee, KRUL-Krumme Lake, MUES-Großer Müggelsee, MUEZ inlet of Großer Müggelsee , LANS-Langer See, PARS-Parsteiner See, ROSS-Rosinsee.

and nitrogen are short cycled. Moreover, these two elements may be intracellularely stored. Therefore total concentrations are better estimators of the nutrient pool for algal growth then are dissolved fractions of either phosphorus or nitrogen.

If molar concentrations $\left[\mu \mathrm{mol} \cdot \mathrm{l}^{-1}\right.$ ] of the three macronutrients are used for triangular graphs it is possible to read the stoichiometric ratios directly (Fig. 5). Each point on the diagram represents the sum of the absolute concentrations equal to $100 \%$. The corners of the triangle represent the concentration of one element only (100\%) and the absence of the remaining two nutrients. Following from $\mathrm{SRSi}=0$ and $\mathrm{TN}: \mathrm{TP}=16: 1$, the percentage ratio of $\mathrm{TN}: \mathrm{TP}$ is $94,12: 5.88$. This point is indicated by the intersection of the TN:TP=16:1 line on TN-TP-axis (Fig. 5). The TN scaling is from left to right and the TP scaling from right to left on this axis. All points on the bold line "16:1" represent ratios of constant TN:TP=16:1 but variable concentrations of SRSi. Points on the 
left side of the line TN:TP=16:1 represent ratios of $\mathrm{TN}: \mathrm{TP}>16$, points on the right side $<16$. The disadvantage of diagrams based on this nutrient ratios is that points fall on a small area because the different concentrations of these three macronutrients differ by several orders of magnitude (Fig. 5). For clearer presentation of the points within the area the concentrations were normalised by the relation of the concentration of an element to its sum over the entire data set $\left(\mathrm{C}_{\text {norm }}=\frac{100 \mathrm{C}}{\sum_{i=1}^{n} \mathrm{C}_{\mathrm{i}}}\right)$. As a result, points representing seasonal $\mathrm{TN}_{\text {norm }}: \mathrm{TP}_{\text {norm }}: \mathrm{SRSi}_{\text {norm }}$ ratios become more scattered and are easier to distinguish, but TN:TP:SRSi ratios can not be read directly. How ever, it is possible to recalculate these ratios. Example in Fig. 4a shows that the $\mathrm{TN}_{\text {norm }}: \mathrm{TP}_{\text {norm }}: \mathrm{SRSi}_{\text {norm }}$ ratio of point b corresponds with the TN:TP:SRSi ratio of point a. For the complex calculations of the 16:1 ratios in normalised diagrams (Figs. 6, 7) refer to TEUBNER (1996).

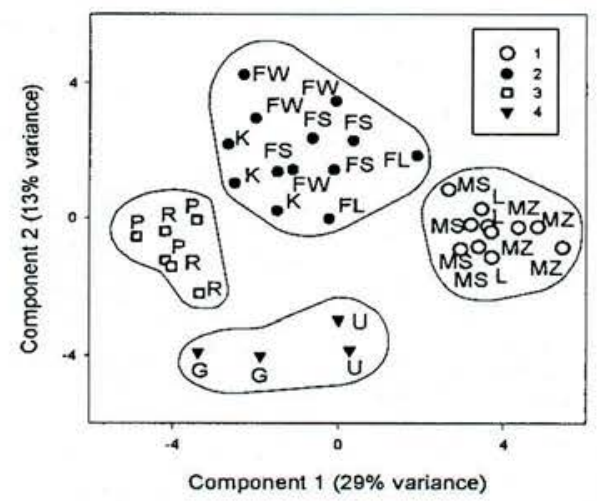

Fig. 3 Plot of the second versus the first principal component for grouping of waters according to phytoplankton dominance. 32 dominant taxa of different algal classes were included: cyanobacteria - Anabaena flos-aquae, A. lemmermannii, Aphanizomenon gracile, A. flos-aquae, Chroococcus spp., Limnothrix redekei, Microcystis aeruginosa, M. viridis, M. wesenbergii, Planktothrix agardhii, diatoms - Actinocyclus normanii, Aulacoseira spp., Cyclostephanos dubius, Cyclotella kuetzingianalocellata/comensis, Fragilaria ulna, Fragilaria crotonensis, Nitzschia acicularis, Stephanodiscus alpinusImedius, S. hantzschii, S. neoastraea, Tabellaria flocculosa, Chlorophyta s.1. - Closterium acutum, Monoraphidium contortum, Tetraselmis spp., Trachelomonas spp., Cryptophyceae - Crytomonas erosalovata, C. marssonii, Rhodomonas lacustris, R. lens, Dinophyceae- Ceratium spp., Gymnodinium spp., Peridinium spp., extraction of algae described in methods.

Triangular diagrams of phytoplankton structure were based on biovolumes of algal classes of single seasons (Fig. 9) or seasonal data averaged for a group of waters (Fig. 10). According to the TN:TP:SRSi diagrams the siliceous Bacillariophyceae and Chrysophyceae were arranged at the top. The cyanobacteria were assigned to the corner of TP because of relationship to low N:P ratios. 
The remaining algae (others: Chlorophyta s.1., Cryptophyceae, Dinophyceae) were placed at the corner of high TN:TP ratios and low silicon concentrations. A scheme for easier interpretation of the triangular diagrams of TN:TP:SRSi and phytoplankton is shown in Fig. 4b.
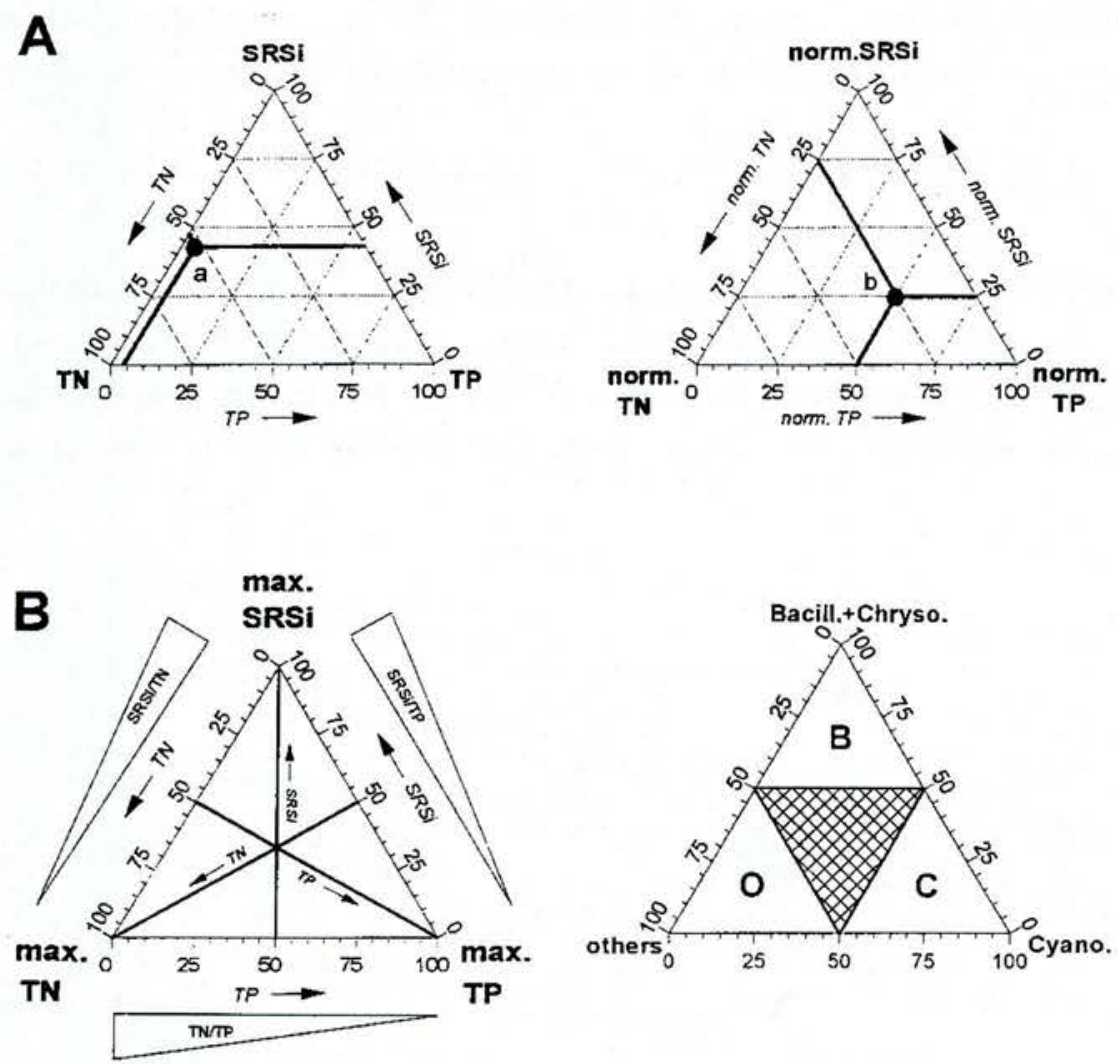

\section{Fig. 4 Triangular TN-TP-SRSi diagrams. Examples how to read the figures.}

A: Left panel, example for relative TN-TP-SRSi concentrations in percent. The point ' $a$ ' in the graph represents the ratio of concentrations of TN:TP:SRSi=52.18:4.99:42.83. The sum of these three relative concentrations is 100 . Right panel, example for normalised TN-TP-SRSi ratios. The point ' $b$ ' represents the standardised ratio of concentrations of $\mathrm{TN}_{\text {norm }}: \mathrm{TP}_{\text {norm }}: \mathrm{SRSi}_{\text {norm }}=25: 30: 25$. The sum of these three concentrations is 100 . This normalised macronutrient ratio can be recalculated to the original TN:TP:SRSi ratio. For $\mathrm{TN}_{\mathrm{norm}}=25$ and $\sum_{i=1}^{\| \prime} \mathrm{TN}_{i}=10255,22$ ( $\mathrm{n}=$ number of seasonal averages $=129$ ) and $\mathrm{TN}_{\mathrm{norm}}=T N / \sum_{i=1} T N_{i}$ the portion of $\mathrm{TN}$ is 256380,5 . Analogously for $\mathrm{TP}=24507.0$ and $\mathrm{SRSi}=210401.75$ the portion of $\sum_{i=1}^{n} \mathrm{TP}_{\mathrm{i}}=490,14$ and of $\sum_{i=1}^{\|} \mathrm{SRSi}_{i}=8416,07$ respectively. Considering TN+TP+SRSi $=256380,5+24507,0+210401,75=491289,25$ the ratio of TN $: \mathrm{TP}: \mathrm{SRSi}=52,18: 4,99: 42,83$ can be found. Therefore, the normalised ratio of concentrations of the point ' $b$ ' in the right panel corresponds to the untransformed ratio of the concentrations of the point ' $a$ ' on the left panel.

B: left panel. The three bisectors of the angle (bold lines) mark the coarse of concentration of the element at the corner from $100 \%$ to $0 \%$ with a constant ratio (1:1) of the remaining two nutrients. right panel. All points in sector C stand for a contribution of at least $50 \%$ cyanobacteria to total phytoplankton biovolume. Analogous sector B 
represents $\geq 50 \%$ Bacillariophyceae and Chrysophyceae and sector $\mathrm{O} \geq 50 \%$ of other algae. The points on the shadowed area indicate, that no algal group exceed $50 \%$ of total biovolume.

\section{Results}

The trophic state of the investigated waters was indicated in Fig. 1 by the total phosphorus and chlorophyll-a according to Forsberg and Ryding (1980). The trophic levels of the waters ranged from meso- to hypertrophic. The grouping of the 11 waters according to eight limnological parameters is shown in Fig. 2. The broken line in the dendrogram of HCA cuts the 11 investigated waters in four groups. These groups are shown in more detail in relation to the limnological variables in the biplot of PCA.

Langer See and Großer Müggelsee are flushed lakes in particular with high concentrations of chlorophyll-a and a high ratio of mixed depth:euphotic depth, caused by turbulent mixing (Fig. 2b, cf. averaged secchi depth in Table 1). The hypertrophic state of both lakes is indicated in Fig. 1. The inlet water of Großer Müggelsee is limnological similar to these riverine lakes. These group is called from now on "hypertrophic riverine lakes". Flakensee, including both inlet waters, and Kiessee are characterised by higher conductivity in comparison to other soft waters (Fig. 2b, cf. Table 1). The highest average conductivity of about $121 \mathrm{mS} \mathrm{m}^{-1}$ was measured in the inlet to Flakensee (FLZW). Therefore this group is called "waters of moderate mineral content". However, the nutrient levels within this group are different indicating that Kiessee is eutrophic, while Flakensee and the inlets are hypertrophic (Fig. 1). Parsteiner See and Rosinsee are deep, mesotrophic lakes with relative low mixed zone $\left(\mathrm{z}_{\text {mix }}\right)$ but high water depth $\left(\mathrm{z}_{\max }\right.$, low $\mathrm{z}_{\text {mix }}: \mathrm{z}_{\max }$ ratio) and high total nitrogen:total phosphorus ratio (TN:TP) caused by low concentrations of TP (Figs. 1, 2; Table 1). These two lakes are labelled "dimictic mesotrophic lakes". Großer Plagesee and Krumme Lake are indicated by high TN:TP ratios too. The averaged TN concentration in Krumme Lake is as high as in the hypertrophic Langer See (Table 1). In the biplot of the PCA Krumme Lake is mainly separated by its extreme high TN concentrations from the three lakes with higher TN:TP ratios (Fig. 2b). Großer Plagesee and Krumme Lake are indicated by the lowest conductivity (Fig. 2b, Table 1). The high TN:TP ratios and low conductivity are in accordance to their dystrophic character. These two lakes are called "dystrophic lakes". In the last two groups, the "dimictic mesotrophic lakes" and the "dystrophic lakes", low silicon concentrations (SRSi) prevail (Fig. 2b, Table 1).

The grouping of waters according to the biovolume of 32 dominant species of different algal classes is shown in Fig. 3. It is obviously, that the limnological grouping coincides with the grouping of waters according to the species dominance.

The relation between the three macroelements - TN, TP and SRSi - of the 11 investigated waters are shown in Fig. 5. All seasonal points of the "dimictic mesotrophic lakes" (3) and the "dystrophic lakes" (4) in the graph are marked by TN:TP ratios higher than $16: 1$. The "dystrophic lakes" are especially characterised by very low SRSi concentration in relation to high TN:TP ratios. In contrast to that, the seasonal relative TN:TP:SRSi ratios of "hypertrophic riverine lakes" 
(1) range from TN:TP $>16$ to $<16$. The "waters of moderate mineral content" show different behaviour of the seasonal changes of relative nutrient ratios. Seasonal changes in Kiessee were restricted to TN:TP ratios higher than 16:1, while that of the Flakensee-waters were mostly lower than $16: 1$ in relation to varying SRSi concentrations.

Because the TN:TP:SRSi ratios can be mathematically transferred to the $\mathrm{TN}_{\text {norm }}: \mathrm{TP}_{\text {norm }}: \mathrm{SRSi}_{\text {norm }}$ ratios (see methods for details and Fig. 4) the results described for Fig. 5 are also valid for Fig. 6. However, the different seasonal changes of the normalised nutrient ratios are presented in Fig. 6 in more detail for the 4 water groups. Additional the seasonal variation of the normalised ratios for Großer Müggelsee, Flakensee, Parsteiner See and Krumme lake, representing each limnological water group, are shown in Fig. 7.

In the case of the "hypertrophic riverine lakes" seasonal points are scattered along all three fictitious bisectors of angles (Fig. 6 (1), bisectors in Fig. 4b). This indicates a high seasonal dynamic of TN, TP as well as SRSi in this water group. Relative high SRSi concentrations in relation to high TN:TP ratios (> 16:1) prevail during winter. From winter to spring the SRSi concentrations drastically declined while the TN:TP ratios remain more or less constant. From spring onwards to summer the TN:TP ratio change drastically from higher than $16: 1$ to lower than $16: 1$. The SRSi concentrations in summer are low in relation to each other elements as in spring. In autumn low TN:TP ratios are comparable with those of summer (TN:TP<16:1) but relative high SRSi concentrations are predominant. From autumn to winter the TN:TP ratio changed back from $<16: 1$ to $>16: 1$. These seasonal changes occurring in the "hypertrophic riverine lakes" in general are also characteristic for a specific lake of this water group, the Großer Müggelsee (Fig. 7).

In contrast to strong seasonal dynamics of all the three elements in the "hypertrophic riverine lakes", the seasonal variation in the other investigated waters were more restricted to only two elements. In the "dystrophic lakes" low SRSi concentrations prevail throughout the season in relation to each other elements (Fig. 6). A higher seasonal dynamic was found for TP and TN. In the Krumme Lake extreme low seasonal variation of SRSi, but a high dynamic of TN:TP is detected from winter/spring to summer/autumn in comparison to Großer Plagesee (Fig. 7).

The nutrient dynamic in the "dimictic, mesotrophic lakes" are characterised by small variation of TP (points arranged parallel to SRSi-TN-axis) in relation to strong variation of TN as well as SRSi (points distributed over a wide range along a fictitious line of variable TN and SRSi concentrations respectively when concentrations of the two other elements remain constant, Fig. 6 , Parsteiner See in Fig. 7). Therefore in this deep lakes a weak dynamic of TN:TP in relation to high seasonal variation of SRSi is detected.

The "waters of moderate mineral content" differ not only in absolute nutrient concentrations, but also in different TN:TP:SRSi ratios (Figs. 1, 6). Because of this heterogeneity within the group, the nutrient ratios are discussed in more detail for Flakensee (Fig. 7). In accordance with "dimictic, mesotrophic lakes" weak TN:TP but strong SRSi variations are found from winter/spring to summer/autumn in Flakensee. The only difference in the variation of TN:TP between Flakensee and Parsteiner See is the variable TP concentration at "constant" TN in Flakensee, 
while TN concentrations vary at "constant" TP in Parsteiner See.

\section{SRSi}

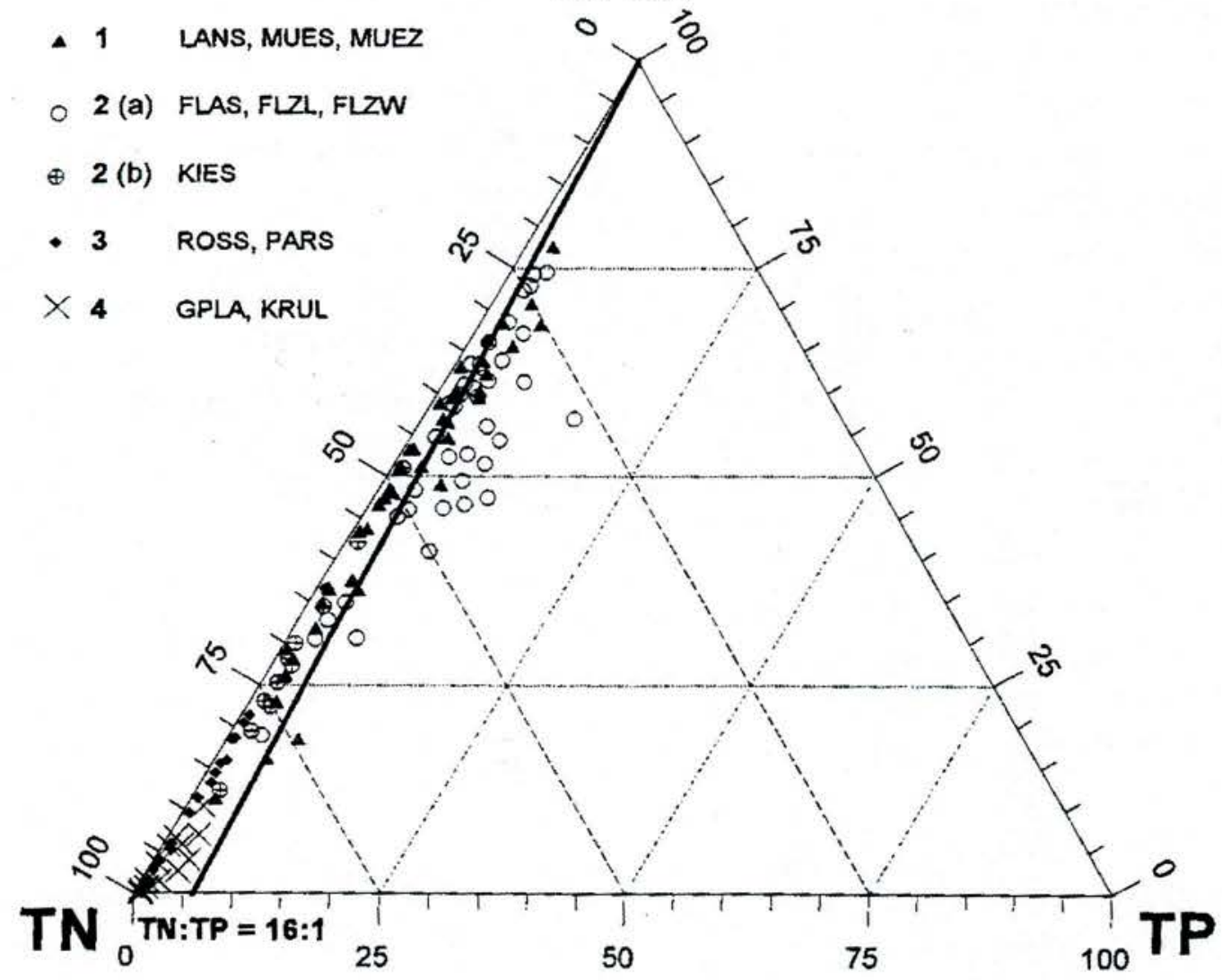

Fig. 5 Triangular diagrams of relative TN:TP:SRSi concentrations of seasons in the four groups of limnological similar waters. For this TN:TP:SRSi ratio the absolute concentrations of these three nutrient elements are considered. Therefore the directly reading of the nutrient ratios is possible. The bold line marks the constant ratio of TN:TP=16:1 in course of variable concentrations of SRSi. Points labelled according to limnological grouping in Fig. 2a (1-"hypertrophic riverine lakes", 2-"waters of moderate mineral content", 3-“dimictic, mesotrophic lakes", 4-“dystrophic lakes”), abbr. of waters see Fig. 2.

Total biovolume and phytoplankton composition of the 11 waters are shown in Fig. 8. Cyanosacteria and Bacillariophyceae are dominant in phytoplankton assemblages of the most investiyated waters. Cyanobacteria are dominant in "hypertrophic riverine lakes" and the eutrophic Krumme Lake ("dystrophic lakes"; Fig. 1). Bacillariophyceae contribute more than $25 \%$ of total biovolume in all 11 waters. With respect to TN:TP:SRSi ratios the phytoplankton biovolume splits into three groups: the siliceous algae (Bacillario-/Chrysophyceae), the cyanobacteria and the renaining algae classes ("others"). The phytoplankton structure of the lake-groups is shown in aigs. 9, 10 according to the relation of biovolumes of these 3 algal groups. 
Only in the "hypertrophic riverine lakes" the seasonal phytoplankton is dominated by at least $50 \%$ Bacillario-/Chrysophyceae or by at least $50 \%$ cyanobacteria (Fig. TP (1), see sectors B and $\mathrm{C}$ in Fig. $4 \mathrm{~b}$ for explanation).
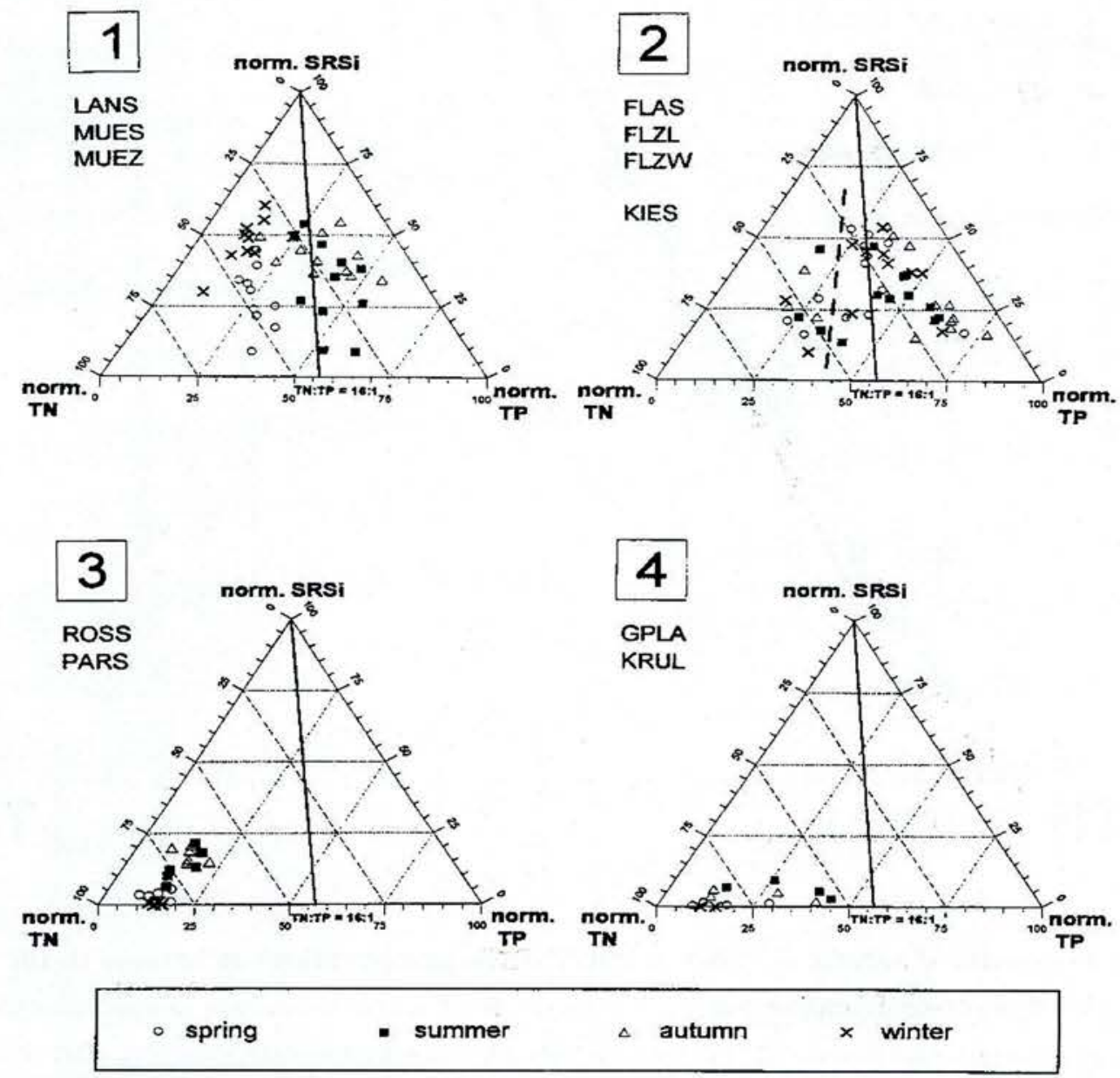

Fig. 6 Triangular diagrams of normalised nutrient element ratios $\left(\mathbf{T N}_{\text {norm }}: \mathbf{T P}_{\text {norm }}: \mathbf{S R S i}_{\text {norm }}\right)$ of seasons in the four groups of limnological similar waters. Every point represents an annual average of winter, spring, summer or autumn of a single water. The bold line marks TN:TP=16:1 (cf. Fig. 5 and methods). The standardisation were based on the data set including all seasonal points of the 11 waters $(n=129)$, but for clarity the results are shown in four displays. Therefore the points of only one water group are presented in a subgraphic. The broken line in subgraphic 2 separate the points of the Flakensee-group (FLAS, FLZW, FLZW, right side) from the Kiessee (left side). Data bases: standardised concentration $=C_{\text {norm }}=100 \mathrm{C} / \sum_{i=1}^{n} C_{i}$; $\sum_{i=1}^{n} T N_{i}=10255,22, \sum_{i=1}^{n} T P_{i}=490,14, \sum_{i=1}^{n} S R S i_{i}=8416,07$, grouping of waters according to Fig. 2 a, recalculation to untransformed nutrient ratios described in method. Water groups see Fig. 2 (1-4), abbr. of waters Fig. 2. 

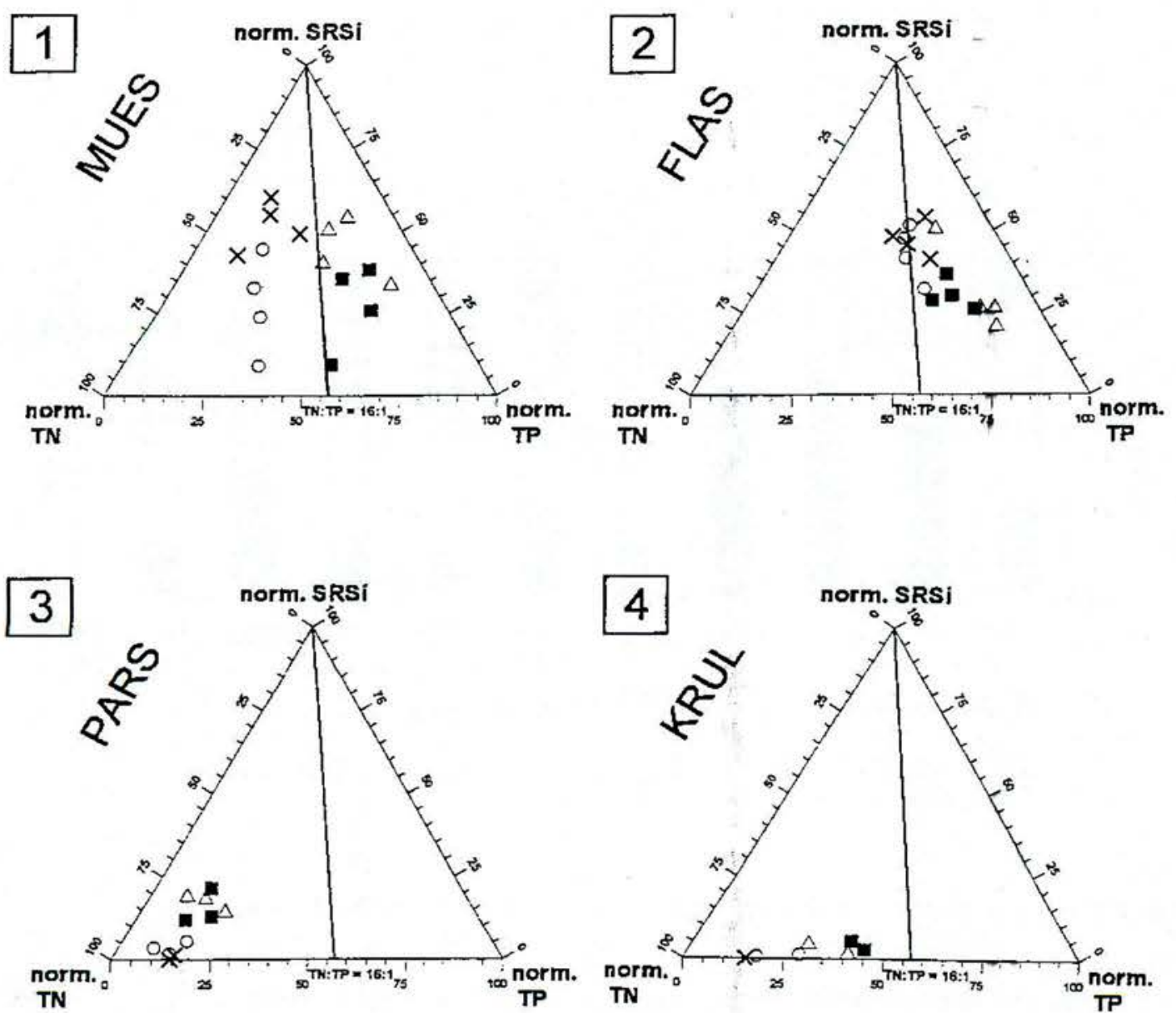

- spring

summer

$\triangle$ autumn

$\times$ winter

Fig. 7 Triangular diagrams of normalised nutrient element ratios $\left(\mathbf{T N}_{\text {norm }}: \mathbf{T P}_{\text {norm }}: \mathrm{SRSi}_{\text {norm }}\right)$ of seasons of four lakes. This lakes are representative for the four limnological groups of waters. Großer Müggelsee for "hypertrophic riverine lakes", Flakensee for "waters of moderate mineral content", Parsteiner See for "dimictic mesotrophic lakes", Krumme Lake for "dystrophic lakes". See also Fig. 6, water groups (1-4) see Fig. 5.

The points representing the seasonal phytoplankton composition in "waters of moderate mineral content" were scattered over the sectors of dominance of Bacillario-/Chrysophyceae and of other alga1 groups as well as a "mixed" plankton of all three algal groups (see shadowed triangle in Fig. 4b). Despite the considerable scatter of the points no preference to cyanobacterial dominance is detected. 

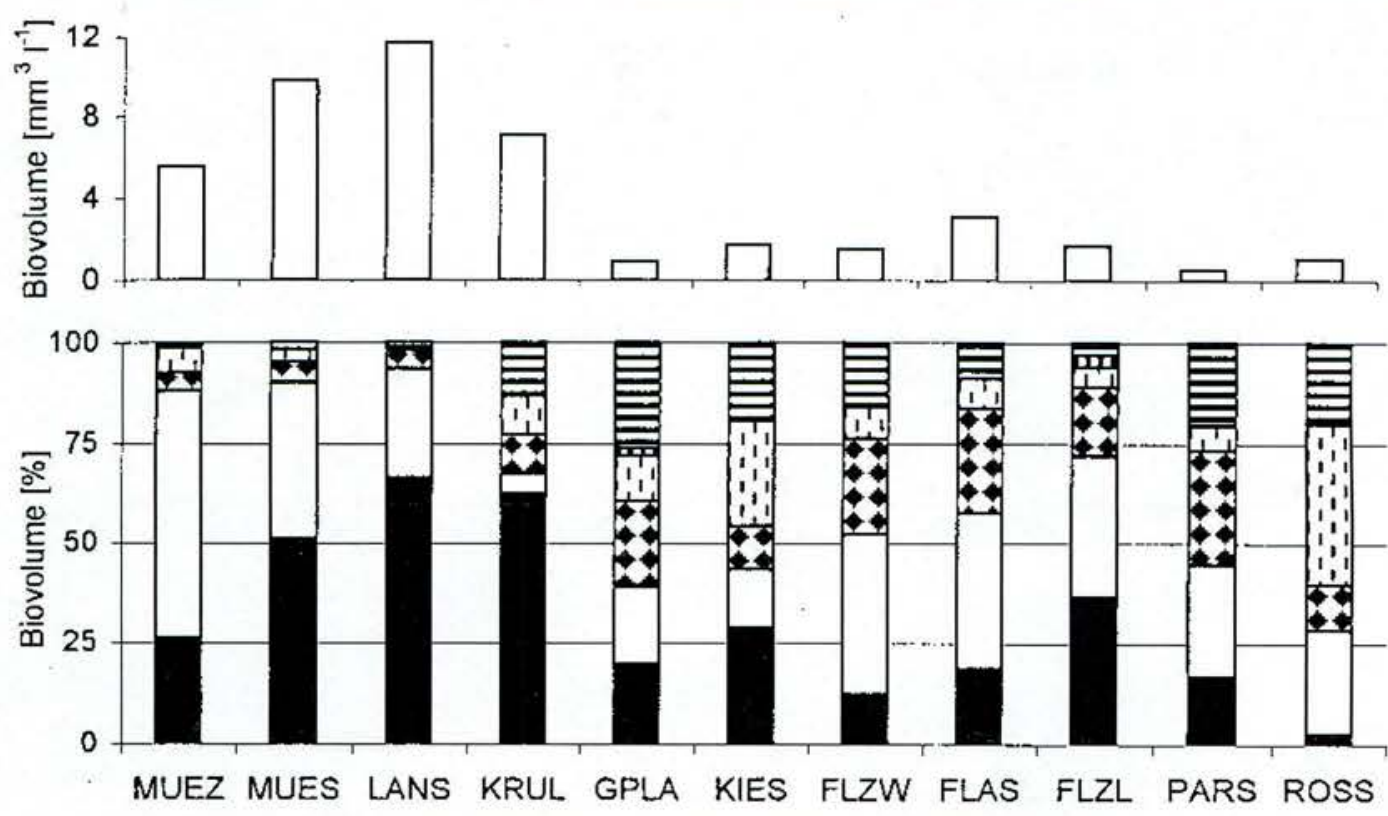
- Cyanobacteria
$\square$ Bacillariophyceae
Cryptophyceae
口Chlorophyta s.I.
W Chrysophyceae
EDinophyceae

Fig. 8 Total biovolume and phytoplankton composition (\%) of the 11 waters.

The seasonal phytoplankton composition of "dimictic, mesotrophic lakes" is mainly restricted to a combination of at least $50 \%$ Bacillario-/Chrysophyceae or of at least $50 \%$ other algae. In contrast, it is a combination of dominating cyanobacteria and dominating other algae in the "dystrophic lakes".

The phytoplankton composition for seasons averaged for all years and waters of a group is shown in Fig. 10. "Hypertrophic riverine lakes" are dominated by Bacillario-/Chrysophyceae in winter and spring and by cyanobacteria in summer and autumn. In correspondence to the scatter of the points per single season in Fig. 9, the averages for the seasons of "waters of moderate mineral content" show no clear preference to one of the three algal groups (intermitted position of points, Fig. 10 (2)). The four mean seasons of phytoplankton biovolume of the "dimictic, mesotrophic lakes" show a clear preference to a plankton dominated by algae other than diatoms and cyanobacteria (Fig. 10 (3)). Obviously, the tendency of variations between seasons is stronger from other algae towards diatoms than it is from other algae to cyanobacteria. The averages of seasonal phytoplankton composition in the "dystrophic lakes" reflect mainly the dominance of other algae or of cyanobacteria (Fig. 10 (4)). Nevertheless differences in seasonal changes between the two dystrophic lakes are obvious. 

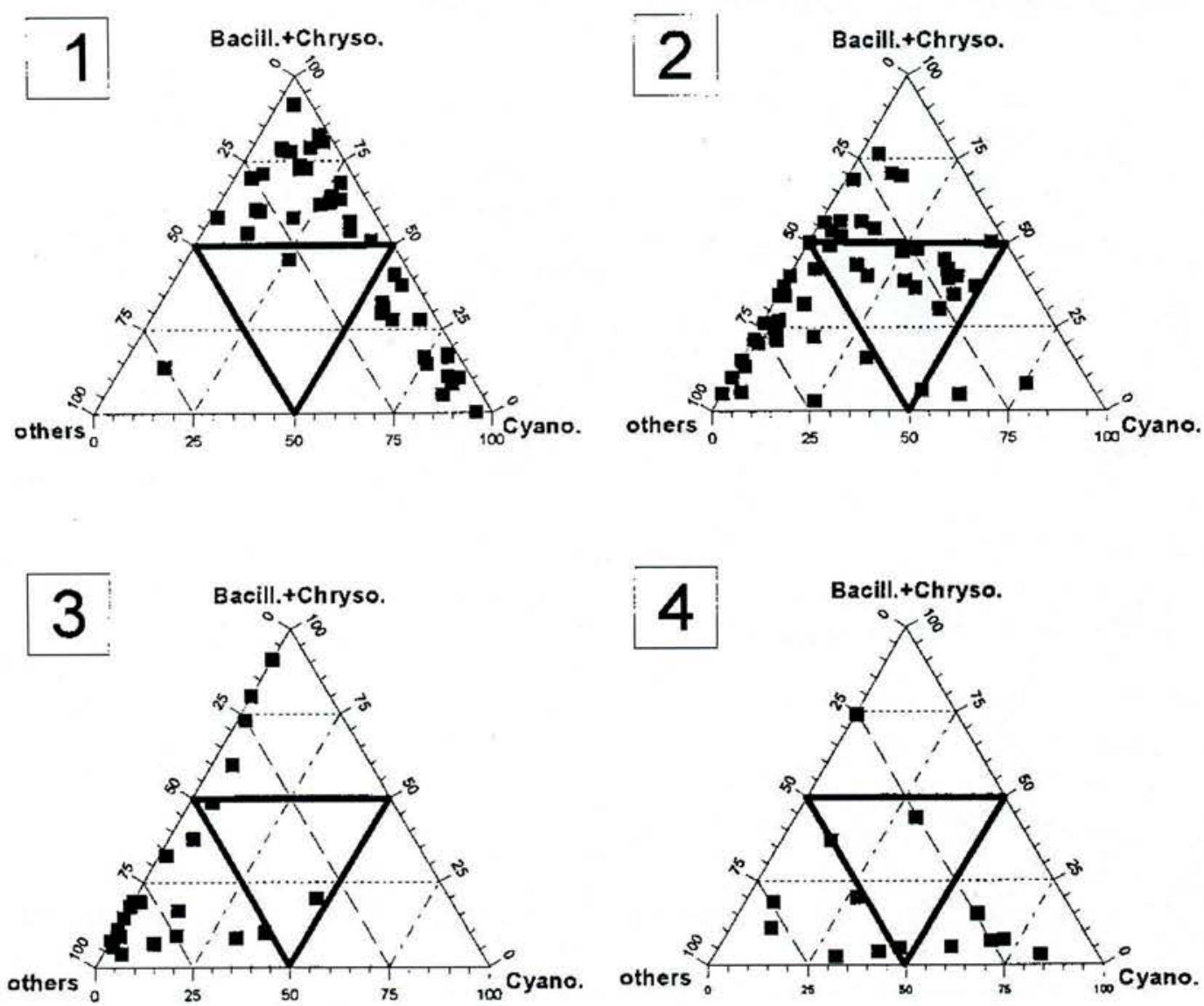

Fig. 9 Triangular diagrams of phytoplankton structure in the four limnological groups of waters. The points are arranged according to the relative biovolume of Bacillario-/Chrysophyceae, of Cyanobacteria and of other algal classes, number of seasonal data (n) of "hypertrophic riverine lakes" (1, n=42), "waters of moderate mineral content" (2, $n=50)$, "dimictic, mesotrophic lakes" ( $3, n=22)$, "dystrophic lakes" $(4, n=14)$. Bold triangle in the central area for easy reading is explained in Fig. 4b. Water groups (1-4) in Fig. 5.

A moderate variation between all three phytoplankton groups is detected for Großer Plagesee. However the comparison between the two dystrophic lakes show, that stronger variation between Bacillario-/Chrysophyceae and other algae were found in Großer Plagesee, while powerful seasonal changes between cyanobacteria and others are accompanied by weak variation of low diatom biovolumes in Krumme Lake.

\section{Discussion}

The importance of nutrient ratios in phytoplankton has been investigated several times. The application of Redfield's ratio to freshwater systems has been discussed by RHEE and GOTHAM (1980) and HECKY et al. (1993). Variations of the N:P ratio in freshwaters have been related to the trophic level and catchment area of lakes (DowNING and McCauly, 1992) as well as to different 
phytoplankton assemblages (BEHRENDT, 1990).
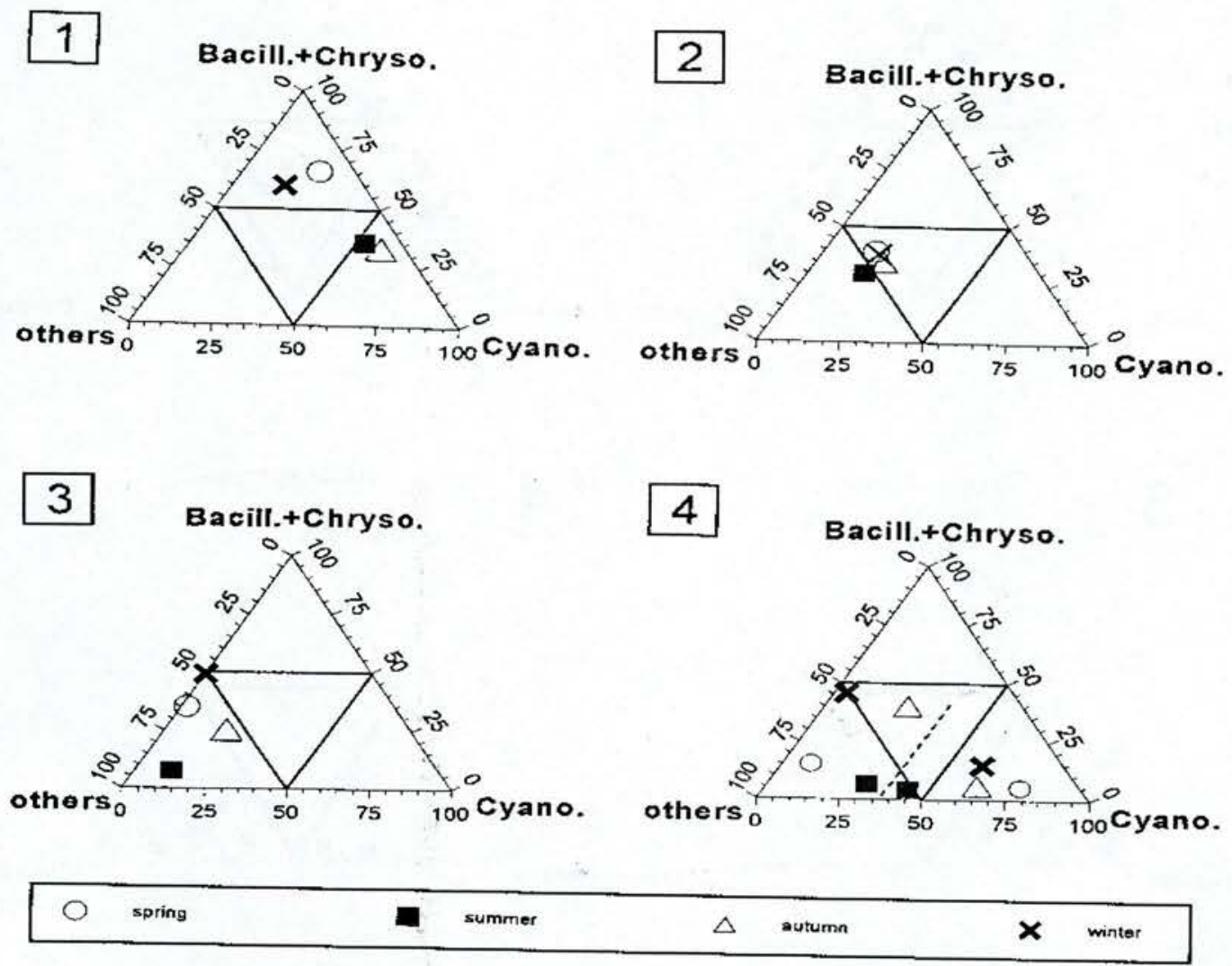

Fig. 10 Triangular diagrams of phytoplankton structure in the four limnological groups of waters. The same as Fig. 9, but based on averaged seasons for each water group. Points labelled according to different seasons. Because of different seasonal phytoplankton structure the two "dystrophic lakes" (4) are separately presented. The broken line separate the points of the Großer Plagesee(left side) from that of Krumme Lake (right side). Abbr. see Fig. 9, water groups see Fig. 5.

The relative nutrient availability (TILMAN, 1982) is of special importance for the seasonal development of algae. It is well established, that low N:P ratios favour the dominance of cyanobacteria during summer (i. a. STEINBERG and HARTMANN, 1988; THOMPSON and RHEE, 1994), especially the nitrogen fixing species during the period of prevailing nitrogen limitation (i. a. TRIMBEE and HARRIS, 1984; SOMMER et al., 1986). SRSi depletion in summer leads to replacement of diatoms by other algae (e.g. cyanobacteria, SOMMER et al., 1986, TIPPMANN, 1993). However, laboratory experiments have shown, that the nutrient ratios of $\mathrm{N}: \mathrm{P}$ or $\mathrm{Si}: \mathrm{P}$ are not only important as such for resource competition, but also the conditions of temperature, light, pulses of nutrient supplies as well as the stage of transition to final equilibrium (TILMAN et al., 1986; SOMMER, 
1983, 1985, 1993; MAKULLA and SOMMER, 1993). Therefore, the outcome of algal competition experiments depend on a combination of nutrient ratios and culture conditions.

Nevertheless, the comparative study of about 404 investigated lake-years of 80 Dutch lakes has shown, that eu- to hypertrophic lakes show a preference for the dominance of only one algal group. From these lakes $46 \%$ were dominated by cyanobacteria, $11 \%$ by diatoms, $40 \%$ by green algae, and 3\% by other groups (SCHREURS, 1992).

Similarly, the comparison on phytoplankton dominance of the 11 water investigated in this study has indicated, that seasons reflect the dominance of only one algal group as well. Except for the heterogeneous group of "waters of moderate mineral content", the seasonal phytoplankton show a clear preference in all other lake-groups for at least $50 \%$ Bacillario-/Chrysophyceae, or at least $50 \%$ cyanobacteria or at least $50 \%$ of algae other than diatoms or blue-greens. This implies that in this spectrum of waters an indifferent phytoplankton composition with moderate contribution of diatoms, cyanobacteria as well as other algae is rare. Division of phytoplankton assemblages into these three algal groups is therefore appropriate for the differentiation of phytoplankton in the 11 investigated meso- to hypertrophic lakes.

The comparison of limnological water groups indicate, that waters, which are different in trophic state and phytoplankton structure, also reflect different seasonal dynamics of the ratios of the three macronutrients.

It is clearly shown, that the "hypertrophic riverine lakes" is the only group with high dynamic of all three elements TN, TP and SRSi in relation to each other during the annual cycles (Fig. 6). In accordance with the scattered data around TN:TP ratios of 16:1 in relation to high fluctuations of SRSi representing a high dynamic of relative nutrient availability, the phytoplankton was dominated by cyanobacteria or diatoms. Nevertheless the high dynamic of all three macroelements in "hypertrophic riverine lakes", the TN:TP, SRSi:TN and SRSi:TP are of different importance for the seasonal changes of phytoplankton. The phytoplankton dominance of the periods winter/spring (at least 50\% Bacillario-/Chrysophyceae) and summer/autumn (at least $50 \%$ cyanobacteria) indicates, that phytoplankton drastically changed from one to the other dominance from spring to summer as well as from autumn to winter (Fig. 10). The changes of the TN:TP ratios were synchronised to this phytoplankton changes. Therefore the changes near the critical TN:TP ratio of 16:1 are of much greater importance than the variations of the SRSi:TN and the SRSi:TP ratios. The phytoplankton development from preferential P (TN:TP>16:1) to preferential N limitation (TN:TP) $<16: 1$ from spring to summer in this shallow, hypertrophic, turbid riverine lakes is shown in detail in TEUBNER et al. (1997).

Contrary to that high dynamic of relative nutrient concentrations in "hypertrophic riverine lakes", high seasonal variations of SRSi in relation to small modifications of TN:TP ratios are found in the "waters of moderate mineral content" (especially Flakensee) and "dimictic, mesotrophic lakes". The only difference in dynamic between the two water groups is, that this small alterations of TN:TP ratios are caused by higher fluctuations of TP in relation to the other elements in Flakensee while high fluctuations of TN are visible in the "dimictic, mesotrophic lakes". Both 
lakes with weak seasonal changes in TN:TP ratios in relation to SRSi show no preference for cyanobacterial dominance. Therefore a low seasonal dynamic of TN:TP in relation to SRSi seems not favourable for cyanobacterial dominance, although TN:TP ratios lower than 16:1 prevail in Flakensee. The absence of cyanobacterial summer-blooms like in "hypertrophic riverine lakes" can be explained by (1) the low variation of TN:TP because of very low TN dynamic and (2) the earlier timing when TN:TP=16:1 is reached. In Großer Müggelsee and Langer See the TN:TP ratio dropped to $16: 1$ at the end of May or early June, while the TN:TP ratio changed from $>16: 1$ to $<16: 1$ usually in March or April in Flakensee (TEUBNER, 1996; TEUBNER et al., 1999). Such an absence of cyanobacterial dominance has been reported in several cases even when conditions should have been favourable for blue-greens because of low N:P ratios (e.g. SOMMER et al., 1986).

According to the relatively high fluctuations of SRSi concentrations in relation to TN and TP in "waters of moderate mineral content" as well as in "dimictic, mesotrophic lakes" higher seasonal variation of diatoms were found (points scattered along the Bacillario-/Chrysophyceae-othersaxis).

In the two "dystrophic lakes" low variation of SRSi are found in combination with moderate (Großer Plagesee) or strong (Krumme Lake) fluctuations in the ratios of TN:TP. Krumme Lake is a dystrophic lake surrounded by marshland. Eutrophication in this lake was recently enhanced through melioration of the catchment resulting in mobilisation of nutrients. Therefore higher seasonal changes in TN:TP ratios were found in this eutrophic lake in comparison to the other dystrophic lake. In accordance with higher fluctuations of TN:TP ratios relative to low variability of SRSi stronger variations between cyanobacteria and "others" occurred in Krumme lake, but modification were low towards diatoms. The diatom bloom was replaced by cyanobacteria especially in spring in this dystrophic lake which is in contrast to the other lakes. With more moderate ratios between the three macronutrients in Großer Plagesee, moderate variability occurs from the "other" algae towards diatoms as well as towards cyanobacteria respectively.

For practical purposes trophic situations are most commonly evaluated from concentrations of a single nutrient or a nutrient ratio, such as N:P. However, a complex assessment would often be more appropriate. In this context triangular diagrams have the benefit of synoptically presenting relative nutrient availability for phytoplankton communities as a whole.

\section{References}

ANwaND, K. 1973. Gewässerverzeichnis der Seen- und Flußfischerei der Deutschen Demokratischen Republik. Institut für Binnenfischerei Berlin-Friedrichshagen, Berlin.

BAILEY-WATTS, A. E., and KiRIKA, A. 1987. A re-assessment of phosphorus inputs to Loch Leven, Kinross, Scotland. rationale and an overview of results on instantaneous loadings with special reference to runoff. Transactions of the Royal Society of Edinburgh: Earth Sciences.78: 351-367. 
BEHRENDT, H. 1990.The chemical composition of phytoplankton and zooplankton in an eutrophic shallow lake, Archiv für Hydrobiologie.118: 129-145.

DownING, J. A., and McCauley, E. 1992. The nitrogen:phosphorus relationship in lakes, Limnol. Oceanogr. 37: 936-945.

FORSBERG, C., and RYDING, S. O. 1980. Eutrophication parameters and trophic state indicies in 30 waste-receiving Swedish lakes, Archiv für Hydrobiologie. 69: 189-207.

GIBBS, J. W. 1878. Abstract of the "Equilibrium of heterogeneous substances", American Journal of Science. 3 (XVI): 441-458.

HeCKy, R. E., CAMPBEll, P., and HendZEL, L. L. 1993. The stoichiometry of carbon, nitrogen, and phosphorus in particulate matter of lakes and oceans, Limnol. Oceanogr.38: 709-724.

MAKUlLA, A., and SOMMER, U. 1993. Relationships between resource ratios and phytoplankton species composition during spring in five north German lakes, Limnol. Oceanogr. 38: 846-856.

PINTO, P., and Morais, M. 1994.The triangular diagrams and the normal bivariate analysis as a new approach to the macroinvertebrate colonization studies. Verh. Internat. Verein. Limnol.25: 1703-1708.

RHEE, G.-Y., and GothAM, I. J. 1980. Optimum N:P ratios and coexistence of planktonic algae. Journal Phycology.16: 486-489.

SANDGREN, C. D. 1988. The ecology of chrysophyte flaggelates: Their growth and perennation strategies as freshwater phytoplankton. In: Growth and reproductive strategies of freshwater phytoplankton, (C. D. Sandgren, ed.), 9-104. Cambridge University Press, Cambridge-New York·Port Chester-Melbourne-Sydney.

SCHREURS, H. 1992. Cyanobacterial dominance - relations to eutrophication and lake morphology, Academisch Proefschrift, Universiteit van Amsterdam.

SOMMER,U. 1983. Nutrient competition between phytoplankton species in multispecies chemostat experiments, Archiv für Hydrobiologie. 96: 399-416.

SOMMER, U. 1985. Comparison between steady state and non-stady competition: Experiments with natural phytoplankton, Limnol. Oceanogr. 30: 335-346.

SOMMER, U. 1993. Phytoplankton competition in Plußsee: A field test of the resource-ratio hypothesis, Limnol. Oceanogr. 38: 838-845.

SOMMER, U., GLIWICZ, Z. M., LAMPERT, W., and DUNCAN, A. 1986. The PEG-model of seasonal succession of planctonic events in fresh waters, Archiv für Hydrobiologie. 106: 433-471.

STEINBERG, C. E. W. and H. M. HARTMAnN.1988. Planktonic bloom-forming cyanobacteria and the eutrophication of lakes and rivers, Freshwater Biology. 20: 279-287.

Teubner, K., Feyerabend, R., Henning, M., Nicklisch, Woitke, A., P., and KoHL, J.-G. 1999. Alternative blooming of Aphanizomenon flos-aquae or Planktothrix agardhii induced by the timing of the critical nitrogen:phosphorus ratio in hypertrophic riverine lakes. Archiv für Hydrobiologie, Spec. Issues Advance. Limnol, 54:325-344. 
TeubNeR, K. 1996. Struktur und Dynamik des Phytoplanktons in Beziehung zur Hydrochemie und Hydrophysik der Gewässer: Eine multivariate statistische Analyse an ausgewählten Gewässern der Region Berlin-Brandenburg.PP.232. Dissertation A, Humboldt-Universität zu Berlin.

TEUBNER, K. 1995. A light microscopical investigation and multivariate statistical analyses of heterovalvar cells of Cyclotella-species (Bacillariophyceae) from lakes of the BerlinBrandenburg region, Diatom Research.10: 191-205.

ThOMPSON, P.-A., and RHEE, G.-Y. 1994. Phytoplankton responses to eutrophication, Arch. ydrobiol. Beih. Ergebn. Limnol.42: 126-166.

TILMAN, D. 1982. Resource competition and community structure.PP.296.In: Monographs in Population Biology, Vol. 17,, R. M. May, ed.), Princeton University Press, Princeton (New Jersey).

Tilman, D., Kiesling, R., Sterner, R., Kilham, S. S., and Johnson, F. A. 1986. Green, bluegreen and diatom algae: Taxonomic differences in competitive ability for phosphorus, silicon and nitrogen, Archiv für Hydrobiologie. 106: 473-485.

TIPPMANN, P. 1993. Zur Bedeutung der Nährstofflimitation für die saisonalen Phytoplanktonsukzessionen in zwei eutrophen Flußseen. Dissertation, Humboldt-Universität zu Berlin.

TrimbeE, A. M., and HARRIS, G. P. 1984. Phytoplankton population dynamics of a small reservoir: Effect of intermittent mixing on phytoplankton succession and the growth of blue-green algae. Journal of Plankton Research.6: 699-713.

VAN DAM, H., SUURMOND, G., and BRAAK, C. J. F., 1981, Impact of acidification on diatoms of Dutch moorland pools. Hydrobiologia .83: 425-459.

VOLLENWEIDER, R. A. 1955. Ein Nomogramm zur Bestimmung des Transmissionskoeffizienten sowie einige Bemerkungen zur Methode seiner Berechnung in der Limnologie. Schweizerische Zeitschrift für Hydrologie. 17: 207-215. 